\title{
Evaluation of Predictive Factors in the Drop-Out Phenomenon: Interaction of Latent Personal Factors and Social-Environmental Context
}

\author{
Valeria Biasi \\ Conny De Vincenzo \\ Sabrina Fagioli \\ Mauro Mosca \\ Nazarena Patrizi \\ Department of Education, \\ "Roma Tre" University, Italy
}

Doi: 10.36941/jesr-2019-0012

\begin{abstract}
This correlational study aims to identify the predictive latent factors of academic failure in a sample of university students not yet at risk of dropping out. 80 healthy students of the first academic year, voluntary recruited through the Ongoing Guidance service at "Roma Tre" University (female = 92\%; mean age = 19 year, 8 months), took part in the study. They completed a battery of questionnaires using the online platform Limesurvey. We computed correlation coefficients (Pearson r) of the relationship between total drop-out score and the measure of cognitive and affective dimensions (STAI, STAXI, OQ45.2, QLS-Italian QSA, ZTPI, AMS, SRKS-U, Questionnaire on the perceived quality of the interaction with the academic setting). Variables which survived Bonferroni correction for multiple comparisons were entered as predictors in a model of multiple regression analysis (stepwise method). The main results indicate that the Drop-Out score is significantly and positively correlated with State, Trait Anxiety and Anger-In scores, and also with the OQ-45.2 subscale (Symptom Distress, Interpersonal Relations and Social Role). Again, the Drop-Out score correlates positively with Anxiety and "Self-regulation" subscales of QLS (QSA). Finally, the students' perception of integration within the University context (quality of social networking, utilization of students' facilities and quality of the interaction with the teachers) appears correlated to specific attitudes or traits. In conclusion, there is evidence to consider the relevance of the social context as a predictive factor in developing the risk of dropping-out, considering the interaction of personality traits or attitudes as latent factors.
\end{abstract}

Keywords: Attitudes, Drop-out risk, Ongoing University Guidance, Perception of integration within University context, Personality traits

\section{Introduction: Recent Empirical Studies on Predictive Factors of University Dropout}

Academic progression, being up to date with exams, are key elements of university success. As is known, however, the current increasing rates of abandonment indicate a strong need for intervention: among OECD countries, about one third of students leave university (OCSE, 2019). University abandonment has negative social consequences, such as fewer qualified employees, as well as personal consequences, such as reduced income, lower perceived happiness, depression and increased stress.

As indicate by Fong, Davis, Kim, Kim, Marriott and Kim (2017) most of the scientific literature 
that examines the factors that influence academic success and non-abandonment of students tends to focus on variables such as socioeconomic status and previously attended school. Although it is essential to identify the basic environmental factors, it is also important to investigate the predictive role of students' cognitive, motivational and behavioral variables: these are factors that affect access, success and permanence in the university (Biasi, De Vincenzo \& Patrizi, 2017).

Respondek, Seufert, Hamm and Nett (2019) have recently highlighted how perceived academic control (PAC) - which refers to how personal beliefs can influence academic achievements - can change in a negative sense during the course of studies. This change can be predictive both with regard to the abandonment of the university and to academic success assessed through the grades obtained. In other words, the decline in student control beliefs is associated with a higher risk of university drop-out and poorer grades. These results highlight the importance of developing evidence-based methods to support student control beliefs.

A previous study conducted by Respondek, Seufert, Stupnisky and Nett (2017) concerning the high risk of university students' academic failure, examined how perceived academic control (PAC) and academic emotions predict undergraduate students' academic success, conceptualized as both low drop-out intention and high achievement. Using a model of structural equations for the overall sample of university students interviewed, it was discovered that perceived academic control was predictive for well-being and positive academic performance, while boredom and anxiety were negative predictive variables. The prediction of the intention of abandonment through perceived academic control was therefore completely mediated by anxiety.

Moreover, with regard to the scientific literature, perceived academic control (PAC) is closely related to self-efficacy (Judge, Erez, Bono \& Thoresen, 2002), as both constructs are part of the expectancy component of students' self-concept (Pintrich \& de Groot, 1990). Furthermore, perceived academic control has a higher impact on academic success than self-esteem (Stupnisky, Renaud, Perry, Ruthig, Haynes \& Clifton, 2007).

Other factors positively related to perceived control are self-regulated learning (Shell and Husman, 2008; Biasi, De Vincenzo \& Patrizi, 2018a, 2018b), effective study strategies used (Cassidy and Eachus, 2000), self-monitoring strategies use and intrinsic motivation (Perry, Hladkyj, Pekrun \& Pelletier, 2001), achievement motivation (Hall, Perry, Ruthig, Hladkyj \& Chipperfield, 2006), and personality constructs such as extraversion or conscientiousness (Perry, Hall \& Ruthig, 2005).

Based on this evidence, we think that by identifying those personal and contextual variables that can be improved through interventions provided by Ongoing University Guidance Services and University Counselling Services, students can be helped to avoid developing the risk of drop-out and to complete the course of study undertaken.

The present correlational study is centered on the identification of these personal and contextual factors.

\section{Aim, Method, Procedure, Instruments, Participants}

\subsection{Aim of the correlational study}

In order to identify the main personal and context variables that can influence the development of drop-out risk, we conducted a correlational study aimed at detecting and measuring the predictive factors of academic failure in a sample of university students not yet at drop-out risk.

\subsection{Participants}

80 healthy students of the first academic year (female $=92 \%$; mean age $=19$ year, 8 months) took part in the study. The participants were voluntary recruited through the Ongoing University Guidance service; each of them signed the informed consent prior to participating in the survey. 


\subsection{Procedure}

Participants were seated at a desk in a sound-attenuated chamber facing a computer screen. All the questionnaires were administered using the online platform Limesurvey (www.limesurvey.org). The participants were briefly introduced to the procedures of the study and were familiarized with the use of the Limesurvey platform. Then, they completed each questionnaire independently in a pre-defined order (see below). The experimenter waited for the completion of each questionnaire and intervened only to load the next one. The overall assessment lasted approximately 2 hours.

\subsection{Measures and Instruments}

We administered the following tools:

a) The Drop-out scale: the students' intentions with regard to continuing their education or dropping out of university were measured with items deriving from Hardre and Reeve's scale (2003). In the original version, the researchers took their cue from the version by Vallerand, Fortier and Guay (1997) to assess the students' intentions to continue or abandon their studies. In the present study, the students were asked the frequency with which they "think they have made a mistake in choosing their degree course", "think of quitting their degree course", "think of changing their degree course", "think of droppingout of university to do something else". For each of the four items, the students' answers were evaluated on a 5-point Likert scale ranging from 1 (Never) to 5 (Always or nearly always).

A Principal Components Analysis (PCA) with a Varimax (orthogonal) rotation of 4 Likert scale items from the Student's intention to Drop-out scale was conducted on data gathered from 68 participants. An examination of the Kaiser-Meyer Olkin measure of sampling adequacy suggested that the sample was factorable $(\mathrm{KMO}=.835)$. The analysis yielded a unique Factor explaining a total of $88.361 \%$ of the variance for the entire set of variables (Biasi, 2019; Fagioli, 2019).

b) The State Trait Anxiety Inventory (STAl): for the measurement of anxiety we used the first (Form Y-1) measures for the anxiety trait and the second (Form Y-2) for the anxiety state (Spielberger, 1983; Spielberger \& Vagg, 1984). Trait anxiety characterizes the individual on an ongoing basis, regardless of the specific context. State anxiety, on the other hand, indicates how much the person perceives his anxiety at a given moment. The test consists of 20 items per factor (State and Trait). The higher the score, the greater the level of anxiety (trait or state).

c) The State-Trait Anger Expression Inventory (STAXI) was developed by Spielberger (1988, 1999; see also Spielberger, Reheiser \& Sydeman, 1995) to assess experience, expression and control of anger. It is a self-report questionnaire including 44 items on a 4-point graded scale, ranging from 1 (completely disagree) to 4 (completely agree). This questionnaire was validated in Italy by Comunian (1992).

The STAXI offers information on how a person feels angry at a given time (State-Anger), how often, easily and intensely the person feels angry over time (Trait-Anger) and what the person does when he feels angry (Anger Expression-In, Anger Expression-Out, AngerControl).

Anger Expression-Out concerns the expression of feelings of anger towards other people or objects; Anger-Control concerns the control of anger expression (Anger Control-Out) or the ways to calm it down (Anger Control-In).

In particular, in this study we will take into account the Anger Expression-In scores that involve holding or suppressing feelings of anger and it can be considered a form of depression, generally associated to the drop-out phenomenon.

d) The OQ-45.2: The Outcome Questionnaire 45.2 by Lambert and Hill_(1994; see also Lambert et al., 1996; Lambert et al., 2006) is a self-report questionnaire that contains 45 items that evaluate the patient's changes following therapeutic treatment. In addition to providing an overall score, the $\mathrm{OQ}-45.2$ also gives three scores for three different 
subscales regarding a) Symptomatic Distress (SD), b) Interpersonal Relations (IR), and c) Social Role (SR).

The answer to each item is given on a 5-point scale (from 0 "Never" to 4 "nearly always"), and the total score is in a range from 0 to 180 points, where the highest score indicates serious and disturbed functioning. Generally, the total score is considered an indicator of the subject's overall functioning. The cut-off score that divides the non-clinical population from the clinical population is estimated on the basis of the value of 64 ; scores above this threshold indicate a pathological condition.

The SD subscale consists of 25 items and measures the psychopathological symptoms that are characteristic of the most common mental disorders, such as anxiety and depression.

The IR subscale consists of 11 items concerning difficulties with interpersonal relations in various life contexts. The IR items assess complaints such as loneliness, conflicts with others, and family and marriage problems. High scores suggest difficulties in these areas, and low scores suggest both the absence of interpersonal problems and satisfaction with the quality of one's intimate relationships.

Finally, the SR subscale consists of 9 items and refers to problems or conflicts in a working, school and/or university context. The SR items measure the extent to which difficulties in the participant's roles as a worker, homemaker or student are present. Conflicts at work, overwork, distress and inefficiency in these roles are assessed. High scores indicate difficulty in social roles, and low scores indicate adequate social role adjustment.

In the Italian validation, Lo Coco et al. (2008) highlighted the use of OQ-45.2 in university counselling services to compare the students' scores before and after the counselling treatment and to evaluate the degree of change that occurs (see also Biasi, Patrizi, Mosca \& De Vincenzo, 2016; Biasi, Patrizi, De Vincenzo \& Mosca, 2017).

e) The Questionnaire on Learning Strategies (QLS; Italian QSA) was developed by Pellerey (1996, 2017) and is widely used as a self-assessment tool for guidance with the aim of supporting and helping young people and adults in transition to secondary school, university or to the world of work. The Questionnaire, available on an online platform, is composed of 100 items, divided into 14 factors, 7 of which are cognitive and the other 7 are affective-motivational.

Cognitive dimensions refer to aspects concerning the use of appropriate processing strategies and the dimensions of planning and control of action, i.e. self-regulatory strategies (see also Margottini, 2017).

The cognitive and metacognitive factors are called: Processing strategies (processes and strategies used to facilitate learning), Self-regulation (the ability to manage the study independently), Disorientation (ability to organise oneself to meet daily commitments), Willingness to collaborate (participatory and collaborative mode of study), Use of semantic organizers (use of diagrams, maps for the organization of the study), Difficulties of concentration, Self-inquiry (tendency to check by self-interrogation of what you have learned).

The affective factors are called: Basic Anxiety (difficulty in controlling and managing one's own emotional reactions), Willingness and will to persevere (perseverance), Attribution of success or failure to controllable causes (tendency to attribute the results achieved to controllable and self-dependent causes, such as commitment), Attribution to uncontrollable causes, Lack of perseverance, Perception of competence (self-perception of personal efficacy in the study), Emotional interference.

f) The Zimbardo Time Perspective Inventory (ZTPI) is a questionnaire developed by Zimbardo and Boyd (1999, 2009) and consists of 56 items; it is possible to express the level of agreement on a 5-point Likert scale.

The questionnaire describes attitudes, beliefs, thoughts and values corresponding to the temporal perspectives towards which people are oriented, relating to five temporal dimensions. Past-Positive (sentimental attitude towards the past), Past-Negative (negative 
view of the past), Present-Fatalistic (fatalistic attitude towards life and the future), Present Hedonistic (hedonistic and risky attitude towards time) and Future (general orientation towards the future, in the perspective that present behavior is dominated by an effort to achieve future goals and rewards) (see also Maggiolaro, 1999).

g) The Academic Motivation Scale (AMS) evaluates the motivation to study and it was developed in relation to the Self-Determination Theory (Vallerand, Pelletier, Blais, Briere, Senecal, \& Vallieres, 1992, 1993). This scale was validated in Italy by Alivernini and Lucidi (2008) and the Italian version of the scale demonstrated good psychometric properties and Cronbach's alpha for the relative subscales ranges from .91 (External Regulation) to .73 (Amotivation). The Academic Motivation Scale consists of five subscales, each composed of four items which are answers to the question "Why are you attending the degree course you are enrolled in?" The five subscales assess: the lack of motivation indicated as "Amotivation": (typical answers include: "I honestly don't know" or "I feel I'm wasting my time in school"); External Regulation ("To get a more prestigious job later"); Introjected Regulation ("Because when I do well in school, I feel important"); Identified Regulation ("Because I think a high school education will help me to best prepare for the career path I have chosen"); Intrinsic Regulation ("Because I get pleasure and satisfaction from learning new things"). The choice of answers for each item are assessed on an 11-point scale ranging from 0 ("Not at all true") to 10 ("Completely true").

h) The Self-Regulated Knowledge Scale - University (SRKS-U), developed on the basis of Pintrich's theory of self-regulated knowledge, was used to assess cognitive strategies. The scale was developed by Pintrich (2004) and validated in Italy by Manganelli, Alivernini, Mallia and Biasi (2015). It is used to measure the frequency with which students implement different cognitive strategies and consists of a 5 -point scale $(1=$ Never; $2=$ Rarely; $3=$ Sometimes; $4=$ Often; $5=$ Always or nearly always). The SRKS-U is composed of five subscales, each consisting of three items that answer the question "When studying, how often do you do the following?".

The five subscales evaluate the use of the following cognitive processes: Knowledge Extraction (frequency with which students select information they consider more important); Knowledge Networking (frequency with which students try to connect new knowledge with what they already know); Knowledge Practice (frequency with which students implement their knowledge); Knowledge Critique (frequency with which students question themselves and criticize what they learn, gaining their own idea); Knowledge Monitoring (frequency with which students monitor their own knowledge). The scale initially consisted of 30 items, but only the 15 best items were later included in the final version of the scale. Thus, compared to the original version of 30 items, a shorter version of 15 items was administered (Biasi, 2019).

i) The Brief Questionnaire on the Perceived Quality of the Interaction with the Academic Setting (in terms of quality of social networking, utilization of students' facilities and quality of the interaction with the teachers; Fagioli \& Biasi, 2018). This scale consists of three items that measure the level of integration of the student with: 1) the Social Context, understood in terms of participation in the activities and the social and cultural initiatives promoted by the university and the construction of a social network; 2) the university context understood in terms of easy Accessibility to the Resources and Services offered by the University; 3) the Teaching Staff, understood as the student's perception of the possibility of coming into direct contact with the teachers and of the quality of the tutoring they offer.

\section{Results}

First, we computed crude correlation coefficients (Pearson $r$ ) of the relationship between total dropout score and measure of cognitive and affective dimensions (STAI, STAXI, OQ-45.2, QLS-Italian QSA, ZTPI, AMS, SRKS-U, Questionnaire on the perceived quality of the interaction with the academic setting). Second, variables which survived Bonferroni correction for multiple comparisons 
$(k=35, p: 0.05 / 35=0.0014)$ were entered as predictors in a model of multiple regression analysis (stepwise method).

Table 1 shows the crude correlation coefficients between the Drop-Out score and all the other questionnaires administrated during the assessment session. The $p$-values for each bivariate correlation were adjusted using Bonferroni's correction and are reported in parentheses.

In summary, the total Drop-Out score appears significantly and positively correlated with the State and Trait Anxiety scores: this emphasizes the role of anxiety also in students not at risk of dropping out.

Moreover, the total Drop-Out scores correlate too with the total score of OQ-45.2, and with the three subscales: Symptom Distress (SD), Interpersonal Relations (IR) and Social Role (SR).

For learning strategies, we observed significative correlations of total Drop-Out score only with three subscales of the first factor of QLS (Italian QSA): a highly significant and positive correlation with the Anxiety subscale and "Lack of perseverance" subscale, and an understandably significant but negative correlation with the "Availability and willingness to persevere" subscale. This means that the risk of drop-out is accompanied by basic anxiety and the loss of the ability to persevere in the effort.

Table 1: Bivariate correlation between Drop-Out scores and cognitive and affective measures in a sample of 80 students not at risk of dropping out.

\begin{tabular}{|c|c|}
\hline Participants $(n=80)$ & \\
\hline Questionnaires & Total Drop-Out * \\
\hline \multicolumn{2}{|l|}{ STAI - State Trait Anxiety Inventory } \\
\hline STAI-S & $0.376(<0.001)$ \\
\hline STAI-T & $0.488(<0.001)$ \\
\hline \multicolumn{2}{|l|}{ STAXI - State Trait Anger Expression Inventory } \\
\hline S-Rab & $0.096(0.398)$ \\
\hline T-Rab & $0.057(0.615)$ \\
\hline $\mathrm{T}-\mathrm{Rab} / \mathrm{T}$ & $0.052(0.650)$ \\
\hline T-Rab/R & $0.007(0.951)$ \\
\hline $\mathrm{AX} / \mathrm{In}$ & $0.433(<0.001)$ \\
\hline AX/Out & $0.099(0.380)$ \\
\hline AX/Con & $-0.155(0.171)$ \\
\hline AX/EX & $0.254(0.023)$ \\
\hline \multicolumn{2}{|l|}{$O Q \circledast-45.2$} \\
\hline Symptom Distress (SD) & $0.522(<0.001)$ \\
\hline Interpersonal Relations (IR) & $0.459(<0.001)$ \\
\hline Social Role (SR) & $0.683(<0.001)$ \\
\hline OQ-Total Score & $0.582(<0.001)$ \\
\hline \multicolumn{2}{|l|}{ Questionnaire on Learning Strategies (QLS; Italian QSA) } \\
\hline A1 - Basic Anxiety & $0.376(<0.001)$ \\
\hline A2 - Willingness and will to persevere & $-0.403(<0.001)$ \\
\hline A3 - Attribution of success or failure to controllable causes & $0.015(0.897)$ \\
\hline A4 - Attribution to uncontrollable causes & $0.230(0.040)$ \\
\hline A5 - Lack of perseverance & $0.489(<0.001)$ \\
\hline A6 - Perception of her/his own skills & $-0.210(0.062)$ \\
\hline A7 - Occasional emotional interference & $0.285(0.010)$ \\
\hline C1 - Processing strategies & $-0.129(0.255)$ \\
\hline C2 - Self-regulation & $-0.348(0.002)$ \\
\hline C3 - Disorientation & $0.316(0.004)$ \\
\hline C4 - Willingness to collaborate & $-0.205(0.068)$ \\
\hline C5 - Use of semantic organizers & $-0.178(0.115)$ \\
\hline C6 - Difficulties of concentration & $0.274(0.014)$ \\
\hline C7 - Self Inquiry & $-0.143(0.206)$ \\
\hline \multicolumn{2}{|l|}{ Zimbardo Time Perspective Inventory (ZTPI) } \\
\hline Past Negative & $-0.46(0.686)$ \\
\hline
\end{tabular}




\begin{tabular}{lc}
\hline Past Positive & $0.310(0.005)$ \\
\hline Present Hedonistic & $-0.229(0.041)$ \\
\hline Present Fatalistic & $-0.287(0.010)$ \\
\hline Future & $0.347(0.002)$ \\
\hline Academic Motivation Scale (AMS) & $0.198(0.078)$ \\
\hline Amotivation & $0.099(0.384)$ \\
\hline External regulation & $0.042(0.711)$ \\
\hline Introjected regulation & $-0.267(0.017)$ \\
\hline Identified regulation & $-0.176(0.117)$ \\
\hline Intrinsic regulation & $-0.189(0.092)$ \\
\hline Self-Regulated Knowledge Scale - University (SRKS-U) & $-0.096(0.398)$ \\
\hline Knowledge Extraction & $0.037(0.743)$ \\
\hline Knowledge Networking & $-0.058(0.609)$ \\
\hline Knowledge Practice & $0.004(0.972)$ \\
\hline Knowledge Critique & \\
\hline Knowledge Monitoring &
\end{tabular}

We must also consider that until now, during the first months of the first academic year, the students are not yet really involved in the preparation of the exams and, as we expected, the academic motivation scores (recorded by AMS) and the self-regulated knowledge scores (detected by SRKS-U) did not yet show any significant correlation with the risk of abandonment. On the other hand, towards the second part of the first university year, after the exam experiences, students can develop the risk of abandonment (Biasi, De Vincenzo \& Patrizi, 2017; Biasi, De Vincenzo \& Patrizi, 2018a; 2018b).

In the same frame, even time orientation, detected by the Zimbardo Time Perspective Inventory (ZTPI), did not yet register significant results during the first months of the first academic year in relation to the drop-out score.

Table 2 illustrates the results of the multiple stepwise regression analysis. Specifically, the standardized coefficients (Beta values) are reported for each predictor in the model, followed by the p-value. As evident, only Social Role (SR), which is a subscale of the OQ-45.2, significantly predict the abandonment score in a sample of participants not at risk.

As we said before, this subscale refers to problems or conflicts in a working, school and/or university context. The SR items measure the extent to which difficulties in the participant's roles as a worker, homemaker or student are present. Conflicts at work, overwork, distress and inefficiency in these roles are assessed.

Thus, the quality of social relations at work, school and university represents a strong variable for the development or not of the risk of academic abandonment.

Table 2: Results of the multiple stepwise regression analysis

\begin{tabular}{lcc}
\hline & Total Drop-Out score \\
\hline & \multicolumn{2}{c}{ Step1 } \\
\hline STAl-S & Beta & $P$ \\
\hline STAl-T & 0.057 & 0.551 \\
\hline AX-IN & 0.061 & 0.587 \\
\hline Symptom Distress (SD) & 0.176 & 0.053 \\
\hline Interpersonal Relations (IR) & 0.084 & 0.475 \\
\hline Social Role (SR) & 0.059 & 0.581 \\
\hline QLS A1 - Basic Anxiety & $\mathbf{0 . 6 8 3}$ & $<\mathbf{0 . 0 0 1}$ \\
\hline QLS A2 - Willingness and will to persevere & 0.076 & 0.418 \\
\hline$F$ & -0.113 & 0.225 \\
$P$ & \multicolumn{2}{c}{68.219} \\
Adjusted R & \multicolumn{2}{c}{$<0.001$} \\
\hline
\end{tabular}

Significant predictors are indicated in bold 
Table 3 illustrates the results of the correlational analysis performed to analyse the association between all variables detected (drop-out risk, cognitive and affective measures, etc.) and the Students' Perception of Integration within the University context.

As said before, the $p$-values for each bivariate correlation were adjusted using Bonferroni's correction and are reported in parentheses.

Table 3: Bivariate correlation between the perceived quality of the interaction with the academic setting (quality of social networking, utilization of students' facilities and quality of the interaction with the teachers) and cognitive and affective measures in a sample of 80 students not at risk of dropping out *.

\begin{tabular}{|c|c|c|c|}
\hline & $\begin{array}{l}\text { Quality of Social } \\
\text { Networking }\end{array}$ & $\begin{array}{l}\text { Utilization of } \\
\text { Student facilities }\end{array}$ & $\begin{array}{l}\text { Teacher-Student } \\
\text { relationship }\end{array}$ \\
\hline Drop-Out Scale & $-0.375(0.001)$ & $-0.301(0.008)$ & $-0.378(0.001)$ \\
\hline STAI-S (State Anxiety Inventory) & $-0.205(0.074)$ & $-0.218(0.056)$ & $-0.233(0.041)$ \\
\hline STAI-T (Trait Anxiety Inventory) & $-0.463(<0.001)$ & $-0.365(0.001)$ & $-0.327(0.004)$ \\
\hline \multicolumn{4}{|c|}{ STAXI - State Trait Anger Expression Inventory } \\
\hline S-Rab & $-0.092(0.427)$ & $-0.086(0.456)$ & $0.054(0.643)$ \\
\hline T-Rab & $-0.303(0.007)$ & $-0.274(0.016)$ & $-0.395(<0.001)$ \\
\hline $\mathrm{T}-\mathrm{Rab} / \mathrm{T}$ & $-0.041(0.722)$ & $-0.054(0.641)$ & $-0.344(0.002)$ \\
\hline T-Rab/R & $-0.381(0.001)$ & $-0.363(0.001)$ & $-0.379(0.001)$ \\
\hline $\mathrm{AX} / \mathrm{In}$ & $-0.368(<0.001)$ & $-0.160(0.165)$ & $-0.109(0.346)$ \\
\hline AX/Out & $-0.357(<0.005)$ & $-0.254(0.026)$ & $-0.347(0.002)$ \\
\hline$\overline{\mathrm{AX} / \mathrm{Con}}$ & $0.166(0.150)$ & $0.152(0.186)$ & $0.314(0.005)$ \\
\hline AX/EX & $-0.322(0.004)$ & $-0.208(0.070)$ & $-0.327(0.004)$ \\
\hline \multicolumn{4}{|l|}{$O Q \circledR-45.2$} \\
\hline Symptom Distress (SD) & $-0.466(<0.001)$ & $-0.398(<0.001)$ & $-0.290(0.010)$ \\
\hline Interpersonal Relations (IR) & $-0.455(<0.001)$ & $-0.380(0.001)$ & $-0.272(0.017)$ \\
\hline Social Role (SR) & $-0.390(<0.001)$ & $-0.442(<0.001)$ & $-0.313(0.006)$ \\
\hline OQ-Total Score & $-0.487(<0.001)$ & $-0.437(<0.001)$ & $-0.315(0.005)$ \\
\hline \multicolumn{4}{|c|}{ (QLS) Questionnaire on Learning Strategies } \\
\hline A1 - Basic Anxiety & $-0.334(0.003)$ & $-0.265(0.020)$ & $-0.468(<0.001)$ \\
\hline A2 - Willingness and will to persevere & $0.308(0.006)$ & $0.248(0.030)$ & $0.347(0.002)$ \\
\hline $\begin{array}{l}\text { A3 - Attribution of success or failure to } \\
\text { controllable causes }\end{array}$ & $0.102(0.378)$ & $0.088(0.444)$ & $0.014(0.903)$ \\
\hline A4 - Attribution to uncontrollable causes & $-0.108(0.349)$ & $-0.061(0.599)$ & $-0.286(0.012)$ \\
\hline A5 - Lack of perseverance & $-0.327(0.004)$ & $-0.322(0.004)$ & $-0.374(0.001)$ \\
\hline A6-Perception of her/his own skills & $0.185(0.108)$ & $-0.005(0.963)$ & $0.161(0.161)$ \\
\hline A7 - Occasional emotional interference & $-0.304(0.007)$ & $-0.325(0.004)$ & $-0.259(0.023)$ \\
\hline $\mathrm{C} 1-$ Processing strategies & $0.203(0.077)$ & $0.076(0.508)$ & $0.273(0.016)$ \\
\hline C2 - Self-regulation & $0.394(<0.001)$ & $0.351(0.002)$ & $0.463(<0.001)$ \\
\hline C3 - Disorientation & $-0.272(0.017)$ & $-0.306(0.007)$ & $-0.241(0.035)$ \\
\hline$\overline{C 4}$ - Willingness to collaborate & $0.210(0.067)$ & $0.085(0.461)$ & $-0.020(0.863)$ \\
\hline C5-Use of semantic organizers & $0.072(0.532)$ & $0.036(0.757)$ & $0.112(0.334)$ \\
\hline C6 - Difficulties of concentration & $-0.302(0.008)$ & $-0.319(0.005)$ & $-0.254(0.026)$ \\
\hline C7 - Self Inquiry & $0.084(0.467)$ & $0.171(0.137)$ & $0.173(0.133)$ \\
\hline \multicolumn{4}{|c|}{ (ZTPI) Zimbardo Time Perspective Inventory } \\
\hline Past Negative & $-0.090(0.435)$ & $-0.096(0.408)$ & $-0.189(0.100)$ \\
\hline Past Positive & $-0.174(0.129)$ & $-0.166(0.148)$ & $0.013(0.908)$ \\
\hline Present Hedonistic & $0.370(<0.001)$ & $0.397(<0.001)$ & $0.399(<0.001)$ \\
\hline Present Fatalistic & $0.177(0.124)$ & $-0.064(0.578)$ & $0.232(0.043)$ \\
\hline Future & $-0.218(0.057)$ & $-0.260(0.022)$ & $-0.185(0.107)$ \\
\hline \multicolumn{4}{|l|}{ (AMS) Academic Motivation Scale } \\
\hline Amotivation & $-0.257(0.024)$ & $-0.265(0.020)$ & $-0.159(0.168)$ \\
\hline External regulation & $-0.217(0.059)$ & $-0.273(0.016)$ & $-0.081(0.484)$ \\
\hline
\end{tabular}




\begin{tabular}{|c|c|c|c|}
\hline Introjected regulation & $-0.215(0.060)$ & $-0.116(0.314)$ & $-0.072(0.532)$ \\
\hline Identified regulation & $0.192(0.094)$ & $0.208(0.070)$ & $0.219(0.055)$ \\
\hline Intrinsic regulation & $0.044(0.703)$ & $0.142(0.217)$ & $0.174(0.129)$ \\
\hline \multicolumn{4}{|c|}{ (SRKS-U) Self-Regulated Knowledge Scale - University } \\
\hline Knowledge Extraction & $0.102(0.376)$ & $0.158(0.170)$ & $0.124(0.284)$ \\
\hline Knowledge Networking & $-0.053(0.647)$ & $-0.029(0.804)$ & $0.126(0.277)$ \\
\hline Knowledge Practice & $-0.114(0.322)$ & $-0.029(0.801)$ & $-0.004(0.971)$ \\
\hline Knowledge Critique & $-0.034(0.771)$ & $-0.001(0.993)$ & $0.089(0.443)$ \\
\hline Knowledge Monitoring & $-0.102(0.378)$ & $-0.050(0.663)$ & $0.043(0.713)$ \\
\hline
\end{tabular}

In short, considering the most robust statistical correlations shown in Table 3, we see that the perceptions of high Quality of Social Networking appear negative related to the Trait Anxiety Inventory (STAI-T score) and to the AX/In (Anger Expression-In).

This means that high level of anxiety and anger directed against themselves (it can be considered a form of depression), are really dysfunctional with respect to integration in the social environment, including the academic one.

From a personality point of view, we confirm that the Basic Anxiety score (A1) plays a dysfunctional role with respect to the quality of Teacher-Student relationship; in fact, these variables are mutually correlated negatively.

Moreover, all the subscales of OQ-45.2 and the total score too, are negatively correlated with the Quality of Social Networking and, in general, also with the Utilization of Student facilities.

Thus, we can consider that students with good relationships with peers and teachers have more possibility to develop a wellbeing in the academic environment and in academic learning.

It appears also relevant and in line with the previous data shown, that the ability to Selfregulation (ability to manage study independently; C2) can be negatively correlated with high Quality of Social Networking and with the perception of good Teacher-Student relationship.

Regarding the (ZTPI) Zimbardo Time Perspective Inventory, we can see that the Present Hedonistic is positively correlated with two perceived aspects of the interaction with the academic setting: the real utilization of students' facilities and the good quality of the interaction with the teachers.

\section{Conclusions}

In conclusion, the main results indicate that the Drop-Out score is significantly and positively correlated with personality traits like the State Anxiety, Trait Anxiety and Anger Expression-In scores, which underline the role of anxiety also in students not at risk of dropping out.

As said before, a high level of anxiety and anger directed against themselves (called also depression), are really dysfunctional with respect to the integration in academic environment.

Moreover, as confirmation of this data, we again found a correlation of Drop-Out score with the Basic Anxiety subscale of the QLS (Italian QSA), and regarding attitude point of view, we found a highly significant and positive correlation with the "Lack of perseverance" subscale, and an understandably significant but negative correlation with the "Availability and willingness to persevere" subscale.

This means that the risk of abandonment is accompanied by both basic anxiety and the loss of the ability to persevere in the effort.

Although the Drop-Out scores correlate with the total score of OQ-45.2, and with all the three subscales: Symptom Distress (SD), Interpersonal Relations (IR) and Social Role (SR), as predictive factor - identified by multiple stepwise regression analysis -, only the Social Role subscale (SR) showed a significant role. This means that especially the quality of social relations at university represents a strong variable on whether the risk of academic drop-out develops or not. Conflicts at work or university, overwork, distress and inefficiency produce a general difficulty in social roles and can have negative consequences on wellbeing and in the learning process. Also, the students' perception of integration within the University context (quality of social networking, utilization of 
students' facilities and quality of the interaction with the teachers) appears to be related to specific personal factors.

Finally, from theoretical point of view, we can consider the relevance of interaction of personal factors and social context in developing the risk of dropping-out.

Personality traits or attitudes seem to play a role as latent factors and the risk of abandonment of studies probably does not take place unless it is linked to environmental deficiencies (i.e. the absence of social support and a deficiency in guidance during the integration process within the university context).

Hence, social support also offered through university services for students represents a sort of protective factor. Based on this evidence, we expect that through interventions on these personal and contextual variables, provided by Ongoing University Guidance Services and University Counselling Services, students can be helped to avoid developing the risk of drop-out and to regularly conclude the study course undertaken.

\section{Acknowledgement}

This paper is the result of the joint work of the five authors. In detail N. Patrizi has wrote paragraphs 1; C. De Vincenzo paragraph 2.2. and $2.4 \mathrm{c}$ ), d), e), f), g), h); V. Biasi has wrote paragraphs 2.1. and 3; S. Fagioli has wrote paragraphs 2.3 and $2.4 \mathrm{a}$ ), b), i). The paragraphs 4 was written in cooperation by V. Biasi and M. Mosca.

This survey was funded in 2019 by the Department of Education ("Roma Tre" University) with the research project entitled "Per un efficace Orientamento Universitario in itinere: il ruolo del colloquio di orientamento e degli strumenti validati di auto-orientamento / For an effective ongoing university guidance: The role of the orientation interview and validated self-orientation tools" (Scientific coordinator: Valeria Biasi).

\section{References}

Alivernini, F., \& Lucidi, F. (2008). The Academic Motivation Scale (AMS): Factorial structure, invariance and validity in the Italian context. Testing, Psychometrics, Methodology in Applied Psychology, 15(4), 211-220.

Biasi, V. (ed.). (2019). Counselling universitario e orientamento. Strumenti e rilevazioni empiriche. Milan: LED.

Biasi, V., De Vincenzo C., \& Patrizi, N. (2017). Relazioni tra autoregolazione dell'apprendimento, motivazioni e successo accademico degli studenti. Identificazione di fattori predittivi del rischio di drop-out. Giornale Italiano di Ricerca Didattica / Italian Journal of Educational Research, 18, 181-198.

Biasi, V., De Vincenzo C., \& Patrizi, N. (2018a). Cognitive strategies, Motivation to learning, levels of Wellbeing and risk of Drop-out: An empirical longitudinal study for qualifying Ongoing University Guidance Services. Journal of Educational and Social Research, 8(2), 79-91. DOI: 10.2478/jesr-2018-0019

Biasi, V., De Vincenzo C., \& Patrizi, N. (2018b). Strategie cognitive per l'autoregolazione dell'apprendimento e motivazione allo studio. Costruzione di Profili medi del funzionamento cognitivo e dell'assetto motivazionale per la prevenzione del drop-out / Cognitive Strategies for Self-regulation of learning and Motivation to study. Construction of average Profiles of cognitive functioning and motivational structure for the prevention of drop-out. Journal of Educational, Cultural and Psychological Studies, 17, 139-159. 10.7358/ecps-2018-017-bias

Biasi, V., Patrizi, N., De Vincenzo C., \& Mosca, M. (2017). I colloqui di orientamento per facilitare il successo accademico: una indagine sperimentale / / The colloquium for university guidance in facilitating academic success: An experimental study. Journal of Educational, Cultural and Psychological Studies, 15, 215-228. DOI: 10.7358/ecps-2017-015-bias

Biasi, V., Patrizi, N., Mosca, M., \& De Vincenzo, C. (2016). The effectiveness of university counselling for improving academic outcomes and wellbeing. British Journal of Guidance \& Counselling, 1-10, 248-257. Published online: 03 Dec 2016 https://doi.org/10.1080/03069885.2016.1263826

Fong, C. J., Davis, C. W., Kim, Y., Kim, Y. W., Marriott, L., \& Kim, S. (2017). Psychosocial Factors and Community College Student Success: A Meta-Analytic Investigation. Rewiew of Educational Research, 87(2), 388-424. DOI, 10.3102/0034654316653479.

Cassidy, S., \& Eachus, P. (2000). Learning style, academic belief systems, self-report student proficiency and academic achievement in higher education. Educ. Psychol. 20, 307-322. doi: 10.1080/713663740

Comunian, A. L. (1992). STAXI. State Trait Anger Expression Inventory. Versione e Adattamento Italiano. Manuale. Florence: O.S. 
Fagioli, S. (2019). Orientamento universitario in itinere: principali modalità e strumenti. In V. Biasi (ed.), Counselling universitario e orientamento. Strumenti e rilevazioni empiriche (pp. 59-71) Milan: LED. DOI: http://dx.doi.org/10.7359/892-2019-fagi

Fagioli, S., \& Biasi, V. (2018). Brief Questionnaire on the Perceived Quality of the Interaction with the Academic Setting. Rome: Didactic and Assessment Laboratory of Learning and Attitudes, "Roma Tre" University.

Hall, N. C., Perry, R. P., Ruthig, J. C., Hladkyj, S., \& Chipperfield, J. G. (2006). Primary and secondary control in achievement settings: a longitudinal field study of academic motivation, emotions, and performance1. Journal of Appl. Soc. Psychol. 36, 1430-1470. doi: 10.1111/j.0021-9029.2006.00067.x

Hardre P. L., \& Reeve J. (2003). A motivational model of rural students' intentions to persist in, versus drop out of, high school. Journal of educational psychology, 95(2), 347.

Judge, T. A., Erez, A., Bono, J. E., \& Thoresen, C. J. (2002). Are measures of self-esteem, neuroticism, locus of control, and generalized self-efficacy indicators of a common core construct? J. Pers. Soc. Psychol. 83, 693-710. doi: 10.1037/0022-3514.83.3.693

Lambert, M. J., Burlingame, G. M., Umphress, V., Hansen, N. B., Vermeersch, D. A., Clouse, G. C., et al. (1996). The reliability and validity of the Outcome Questionnaire. Clinical Psychology \& Psychotherapy, 3(4), 249-258. doi:10.1002/(SICI)1099- 0879(199612)3:4I;249::AID-CPP106[;3.0.CO;2-S.

Lambert, M. J., \& Hill, C. E. (1994). Assessing psychotherapy outcomes and processes. In A. E. Bergin \& S. L. Garfield (Eds.), Handbook of psychotherapy and behavior change (pp. 72-113). New York: John Wiley.

Lambert, M. J., Morton, J. J., Hatfield, D., Harmon, C., Hamilton, S., Shimokawa, K., et al. (2004). Administration and scoring manual for the OQ45.2. Stevenson, MD: American Professional Credentialing Services, LLC.

Lo Coco, G., Chiappelli, M., Bensi, L., Gullo, S., Prestano, C., \& Lambert, M. J. (2008). The factorial structure of the Outcome Questionnaire-45: A study with an Italian sample. Clinical psychology and Psychotherapy, 15(6), 418-423.

Maggiolaro, E. (1999). La Prospettiva Temporale nell'adolescenza. Studio teorico-metodologico. Psychofenia: Ricerca ed Analisi Psicologica, 3, 51-75.

Manganelli, S., Alivernini, F., Mallia. L., \& Biasi, V. (2015). The development and psychometric properties of the "Self-Regulates Knowledge Scale - University" (SRKS-U) / Sviluppo e proprietà psicometriche della "Scala di Auto-Regolazione degli Apprendimenti - Università" (SARA-U). Journal of Educational, Cultural and Psychological Studies, 12, 235-254. DOI: 10.7358/ecps-2015-012-mang

Margottini, M. (2017). Competenze strategiche a scuola e all 'università. Esiti d 'indagini empiriche e interventi formativi. Milan: LED.

OCSE (2019). Education at a Glance 2019. http://www.oecd.org/education/education-at-a-glance/

Pellerey, M. (1996). Questionario sulle strategie di apprendimento (QSA). Rome: LAS.

Pellerey, M. (ed.). (2017). Soft Skill e Orientamento Professionale. Rome: Cnos-Fap.

Perry, R. P., Hall, N., \& Ruthig, J. (2005). Perceived (Academic) control and scholastic attainment in higher education. Higher Education: Handbook of Theory and Research. Higher Education: Handbook of Theory and Research, 22, ed. J. Smart (Dordrecht; Heidelberg; New York, NY; London: Springer), 363-436.

Perry, R. P., Hladkyj, S., Pekrun, R. H., \& Pelletier, S. T. (2001). Academic control and action control in the achievement of college students: a longitudinal field. J. Educ. Psychol. 93, 776-788. doi: 10.1037//00220663.93.4.776

Pintrich P. R. (2004). A conceptual framework for assessing motivation and self-regulated learning in college students. Educational Psychology Review, 16(4), 385-407.

Pintrich, P. R., \& de Groot, E. V. (1990). Motivational and self-regulated learning components of classroom academic performance. J. Educ. Psychol. 82, 33-40. doi: 10.1037/0022-0663.82.1.33

Respondek, L., Seufert, T., Hamm, J. M., \& Nett U. E. (2019) Linking Changes in Perceived Academic Control to University Dropout and Univerity Grades: A Longitudinal Approach. Jurnal of Educational Psichology, Advance online publication. http://dx.doi.org/10.1037/edu0000388

Respondek, L., Seufert, T., Stupnisky, R., \& Nett U. E. (2017). Perceived Academic Control and Academic Emotions Predict Undergraduate University Student Success: Examining Effects on Dropout Intention and Achievement. Front Psychol., 8, 243. doi: 10.3389/fpsyg.2017.00243

Shell, D. F., \& Husman, J. (2008). Control, motivation, affect, and strategic self-regulation in the college classroom: a multidimensional phenomenon. J. Educ. Psychol. 100, 443-459. doi: 10.1037/00220663.100.2.443

Spielberger, C. D. (1983). Manual for the State-Trait Anxiety Inventory. Palo Alto: Consulting Psychologist Press.

Spielberger, C. D. (1988). State-Trait-Anger-Expression-Inventory. Palo Alto, CA: Consulting Psychologist Press.

Spielberger, C. D. (1999). State-Trait Anger Expression Inventory-2 (STAXI-2). Professional Manual. Tampa, FL: Psychological Assessment Resources. 
Spielberger, C. D., Reheiser, E. C., \& Sydeman, S. J. (1995). Measuring the Experience, Expression, and Control of Anger. Issues in Comprehensive Pediatric Nursing, 18(3), 207-232.

Spielberger, C., \& Vagg, P. (1984). Psychometric properties of the STAl: a reply to Ramanaiah, Franzen, and Schill. Journal of Personality Assessment, 48(1), 95-97.

Stupnisky, R. H., Renaud, R. D., Perry, R. P., Ruthig, J. C., Haynes, T. L., \& Clifton, R. A. (2007). Comparing self-esteem and perceived control as predictors of first-year college students' academic achievement. Social Psychol. Educ. 10, 303-330. doi: 10.1007/s11218-007-9020-4

Vallerand, R. J., Fortier, M. S., \& Guay, F. (1997). Self-determination and persistence in a real-life setting: Toward a motivational model of high-school drop out. Journal of Personality and Social Psychology, 72, $1161-1176$.

Vallerand. R. J., Pelletier, L. G., Blais, M. R., Briere, N. M., Senecal, C., \& Vallieres, E. F. (1992). The Academic Motivation Scale: A measure of intrinsic, extrinsic, and amotivation in education. Educational and psychological measurement, 52(4), 1003-1017.

Vallerand, R. J., Pelletier, L. G., Blais, M. R., Briere, N. M., Senecal, C., \& Vallieres, E. F. (1993). On the assessment of intrinsic, extrinsic and amotivation in education: Evidence of concurrent and construct validity of the Academic Motivation Scale. Educational and Psychological Measurement, 53, 159-172.

Zimbardo, P. G., \& Boyd, J. N. (1999). Putting time in perspective: A new individual differences metric. Unpublished manuscript. Italian edition, Id., II paradosso del tempo. La nuova psicologia del tempo che cambierà la tua vita. Milan: Mondadori, 2008. 